\title{
Chemotherapeutic compounds and Acanthamoebae from eye infections
}

\author{
J. NAGINGTON AND JOY E. RICHARDS
}

From the Public Health Laboratory Service, Hills Road, Cambridge CB2 $2 Q W$

SYNOPSIS The amoebicidal and amoebistatic action in vitro of 24 compounds was tested on two strains of Acanthamoeba, A. polyphaga and A. castellanii, isolated from eye infections in this? country. For comparison, the Ryan strain of $A$. castellanii and Naegleria gruberi L-1 were also 0 examined.

Nine compounds showed sufficient activity to merit further consideration, ie, acriflavine, pro- $\frac{\dot{\infty}}{\infty}$ flavine, hydroxystilbamidine isethionate, paromomycin, miconazole, amphotericin, neomycin, polymyxin, and the last two combined in Neosporin.

The recent discovery of progressive destructive corneal ulceration associated with Acanthamoeba polyphaga and $A$. castellanii in this country (Nagington $e t$ al, 1974) and $A$. polyphaga in the USA (Jones, 1973) drew attention to the need for effective chemotherapy.

Most of the reports on amoebicidal agents have been concerned with the treatment of Naegleria infections because of the predominance of Naegleria sp in primary amoebic meningoencephalitis (Carter, 1972), and only a few authors have discussed Acanthamoeba sensitivity (Culbertson et al, 1965; Červa, 1969; Casemore, 1970) because the incidence of human infections is so very low and there has been little need for therapeutic information.

The serious nature of ocular invasion by Acanthamoebae, which resulted in loss of the eye in four of the five patients, made it essential to obtain some information, even if preliminary, of compounds that might be of value.

The readiness with which Acanthamoebae encyst also drew attention to the need to find compounds with cysticidal activity to ensure that cessation of treatment is not followed by re-emergence of active trophozoites.

A strain of Naegleria was included to see if the two genera were likely to behave in the same way.

\section{Material and Methods}

AMOEBAE

A. polyphaga Elliott and A. castellanii Gresham were

Received for publication 25 November 1975 isolated in this laboratory (Nagington et al, 1974) $\vec{\oplus}$ and definitive identification was made by F. C. Page. and D. C. Warhurst (personal communication).

$A$. castellanii Ryan was originally isolated by Pereira et al (1966), identified by Warhurst and Armstrong (1968), and provided by W. P. Stamm as a well characterized strain for comparison.

Naegleria gruberi L-1 provided by D. C. Warhurst $\stackrel{2}{\Rightarrow}$ was isolated originally from an encephalitis infection $\frac{0}{3}$ in Bristol (Apley et al, 1970).

The chemotherapeutic compounds were selected on the basis of previously published work or known amoebicidal or fungicidal properties.

\section{Methods}

Initial tests were made by the generally accepted음 technique of adding the compound to an activelys growing culture of amoebae and then observing the results microscopically (Červa, 1969; Casemore, N 1970; Jamieson, 1975).

This was discontinued because it did not resemble 0 the clinical conditions, in which treatment was likelyew to be tolerated for only a limited time and duringo which encystment was probable, after whicho excystment could occur. Some compounds which arê known to give toxic residues, eg, hydroxystilbami? dine, gave exaggerated titres with the original methodo whereas others gave apparently poor results because of their mainly amoebistatic action, eg, amphotericin

The method finally selected was based on paralle $\mathbb{B}$ tests in order to compare the activity of each come pound on a suspension of active trophozoites for 
amoebicidal action with the action on a suspension of cysts for cysticidal action.

\section{Amoebicidal tests}

An inoculum of Acanthamoebae was obtained by culture in Stamm's medium (SB) (dextrose 0.06 g, sodium chloride $0.05 \mathrm{~g}$, yeast extract $0.02 \mathrm{~g}$ per 100 $\mathrm{ml}$ distilled water to which was added a thick suspension of an overnight culture of a strain of Escherichia coli heated at $60^{\circ} \mathrm{C}$ for $60 \mathrm{~min}$ (Stamm, W. P., personal communication, 1974)), or Casemore's (1970) proteose-peptone glucose medium, for 4-5 days at room temperature or confluent HEp2 tissue culture, maintained in Eagle's Basal Medium with $0.1 \%$ bicarbonate and without added serum, at $37^{\circ} \mathrm{C}$. Naegleria were grown only in SB at both temperatures. $\mathbf{0} \cdot 1 \mathrm{ml}$ of suspension was adjusted to contain about $5 \times 10^{3}$ amoebae with very few cysts and added to $0.9 \mathrm{ml} \mathrm{SB}$, and then $0.1 \mathrm{ml}$ of fresh 10 -fold dilutions of test compound was added.

Solutions were freshly prepared according to the manufacturers' instructions and control tests were made of all diluents. A maximum final concentration of $10^{3} \mu \mathrm{g} / \mathrm{ml}$ was selected as often a higher dosage can be tolerated by the eye than is possible systemically.

\section{Cysticidal tests}

Cysts were obtained from old cultures with negligible trophozoites after being held for weeks at $4^{\circ} \mathrm{C}$ and diluted to give an inoculum of $5 \times 10^{2}$ cysts in $0 \cdot 1$ $\mathrm{ml}$.

All tubes were incubated at $37^{\circ} \mathrm{C}$ for 48 hours, examined for active amoebae by microscopy, and then amoebae and cysts were deposited by centrifugation for $10 \mathrm{~min}$ at $1500 \mathrm{rev} / \mathrm{min}$, supernatant was discarded, and a drop containing most of the deposit was placed on a $1.5 \%$ Noble agar plate. A drop of living $E$. coli suspension was placed adjacent and overlapping the first drop to provide food and further to dilute residual activity of the compound under test.

Plates were sealed with tape and incubated at room temperature, and the whole inoculated area was searched by $\times 10$ objective for living amoebae during the next 5-7 days. A fairly rigorous set of readings was selected and they were defined as follows:

Minimal inhibitory concentration (MIC): Lowest concentration of test compound which produced obvious reduction in number of trophozoites when inspected at $\mathbf{4 8}$ hours.

Amoebicidal concentration (AC): Lowest concentration after exposure to which no living trophozoites could be found after 7 days, ie, $100 \%$ amoebicidal dose.

Cysticidal concentration (CC): Lowest concentration after exposure to which a suspension of cysts gave no recoverable trophozoites, ie, $100 \%$ cysticidal dose.

Minimal cytotoxic dose: Lowest concentration to produce obvious cytotoxic change in HEp2 tissue cultures not containing amoebae.

\section{Results}

Repeated tests showed a working correlation but the degree of constancy was less than with bacterial

\begin{tabular}{|c|c|c|c|c|c|c|c|c|c|}
\hline \multirow[t]{3}{*}{ Compound } & \multirow{3}{*}{$\begin{array}{l}\text { Minimum } \\
\text { Cytotoxic } \\
\text { Dose }\end{array}$} & \multirow{2}{*}{\multicolumn{2}{|c|}{$\begin{array}{l}\text { A. polyphaga } \\
\text { Elliott }\end{array}$}} & \multicolumn{4}{|c|}{ A. castellanii } & \multirow{2}{*}{\multicolumn{2}{|c|}{$\begin{array}{l}\text { N. gruberi } \\
L-I\end{array}$}} \\
\hline & & & & \multicolumn{2}{|c|}{ Gresham } & \multicolumn{2}{|l|}{ Ryan } & & \\
\hline & & $M I C$ & $C C$ & $M I C$ & $C C$ & $M I C$ & $C C$ & $M I C$ & $C C$ \\
\hline $\begin{array}{l}\text { Acriflavine hydrochloride } \\
\text { May and Baker }\end{array}$ & 10 & 1 & 10 & $0 \cdot 1$ & $10^{2}$ & 10 & $10^{2}$ & 1 & $>10^{3}$ \\
\hline $\begin{array}{l}\text { Paromomycin sulphate (Humatin) } \\
\text { Parke Davis }\end{array}$ & $>10^{3}$ & 1 & $10^{2}$ & 1 & $10^{3}$ & 10 & 10 & $10^{2}$ & $10^{2}$ \\
\hline $\begin{array}{l}\text { Hydroxystilbamidine isethionate } \\
\text { May and Baker }\end{array}$ & $10^{3}$ & 1 & $10^{3}$ & 1 & $10^{3}$ & 10 & 10 & $10^{2}$ & $>10^{3}$ \\
\hline $\begin{array}{l}\text { Proflavine hemisulphate } \\
\text { May and Baker }\end{array}$ & 10 & $10^{2}$ & $10^{3}$ & 10 & $10^{3}$ & 10 & $10^{3}$ & $10^{2}$ & $>10^{3}$ \\
\hline $\begin{array}{l}\text { Miconazole nitrate } \\
\text { Ortho }\end{array}$ & 10 & 10 & $10^{3}$ & $10^{2}$ & $10^{3}$ & $10^{2}$ & $10^{3}$ & 10 & $10^{2}$ \\
\hline $\begin{array}{l}\text { Amphotericin B (Fungizone) } \\
\text { Squibb }\end{array}$ & $10^{2}$ & 1 & $10^{3}$ & 1 & $>10^{3}$ & 10 & $10^{3}$ & $0 \cdot 1$ & 10 \\
\hline $\begin{array}{l}\text { Polymyxin B } \\
\text { Burroughs Wellcome }\end{array}$ & $10^{3}$ & 10 & $>10^{3}$ & 10 & $10^{3}$ & 1 & $>10^{3}$ & 1 & $>10^{3}$ \\
\hline $\begin{array}{l}\text { Neosporin } \\
\text { Burroughs Wellcome }\end{array}$ & $10^{2}$ & 1 & $10^{3}$ & 1 & $>10^{3}$ & 1 & $>10^{3}$ & 10 & $10^{3}$ \\
\hline $\begin{array}{l}\text { Neomycin sulphate } \\
\text { Burroughs Wellcome }\end{array}$ & $>10^{3}$ & 1 & $>10^{3}$ & 10 & $2 \times 10^{2}$ & 1 & $>10^{3}$ & 10 & $4 \times 10^{2}$ \\
\hline $\begin{array}{l}\text { Clotrimazole (Canesten) } \\
\text { Bayer }\end{array}$ & $10^{2}$ & $0 \cdot 1$ & $>10^{3}$ & 1 & $>10^{3}$ & 1 & $>10^{3}$ & $10^{2}$ & $>10^{3}$ \\
\hline
\end{tabular}

Table I The 10 most active compounds

Concentrations in $\mu \mathrm{g} / \mathrm{ml}$. All tests in broth at $37^{\circ}$ for $48 \mathrm{~h}$. 
assays. For this reason we have restricted ourselves to 10 -fold dilution differences.

The 10 compounds with appreciable activity are shown in approximate order of activity in table $\mathbf{I}$. For simplicity only the MIC and CC are given, the amoebicidal concentration being intermediate. Table I is based on exposure to the test compound in SB for 48 hours as above. When the 48 hours' exposure was carried out in HEp2 tissue culture there was generally less inhibitory action which was, however, only markedly less with paromomycin and clotrimazole.

The first nine compounds appear worth further investigation, having an AC activity at $10^{3} \mu \mathrm{g} / \mathrm{ml}$ or better. Clotrimazole appears to have a very poor AC and $\mathrm{CC}$ action despite the very low MIC, and this may help to explain the observations of Jamieson (1975) who found very poor in vivo protection of mice against $N$. fowleri.

The nine compounds can be arbitrarily grouped according to activity (table II) because the response of the three Acanthamoebae strains to them is fairly comparable.

It will be seen that the outstanding difference is the high degree of susceptibility of Acanthamoebae to acriflavine and proflavine, which was less marked with $N$. gruberi L-1. The well marked sensitivity of Naegleria to amphotericin (Carter, 1969) was evident but it was not found to have comparable AC and C.C action on the Acanthamoebae.

Several compounds appeared to have a relatively specific anti-amoebic activity when judged by an MIC at least 100 -fold less than the HEp2 cytotoxic dose. These were paromomycin, amphotericin, polymyxin, and neomycin. Hydroxystilbamidine appeared specificially active only against the Acanthamoebae.

Cytotoxicity was evident in the case of the disin-

\begin{tabular}{lll}
\hline & Acanthamoebae & Naegleria gruberi $L-1$ \\
\hline $\begin{array}{l}\text { A Cysticidal at } 10^{2} \\
\mu \mathrm{g} / \mathrm{ml} \text { or better }\end{array}$ & Acriflavine & $\begin{array}{l}\text { Amphotericin } \\
\text { Miconazole }\end{array}$ \\
$\begin{array}{l}\mathrm{B} \text { Cysticidal at } \\
10^{3} \mu \mathrm{g} / \mathrm{ml}\end{array}$ & $\begin{array}{l}\text { Paromomycin } \\
\text { Hydroxystilbamidine } \\
\text { Proflavine } \\
\text { Miconazole }\end{array}$ & $\begin{array}{l}\text { Paromomycin } \\
\text { Neosporin } \\
\text { Neomycin }\end{array}$ \\
$\begin{array}{l}\mu \mathrm{g} / \mathrm{ml} \text { but AC at } \\
10^{3} \mu \mathrm{g} / \mathrm{ml} \text { or better }\end{array}$ & $\begin{array}{l}\text { Amphotericin } \\
\text { Polymyxin }\end{array}$ & $\begin{array}{l}\text { Acriflavine } \\
\text { Proflavine } \\
\text { Neomycin }\end{array}$ \\
Neosporin & Pydyyxin \\
\hline
\end{tabular}

Table II Grades of activity and comparison of action on Acanthamoeba and Naegleria strains

${ }^{1}$ Paromomycin is markedly less active in tissue culture. fectant compounds acriflavine and proflavine although this may not preclude their topical use.

The 15 compounds tested that were found to have no appreciable activity are tabulated in table III.

\begin{tabular}{ll}
\hline Compound & Manufacturer \\
\hline (Berenil) a diamidine diaceturate trypanocide & Hoechst \\
Chloroquin sulphate & May and Baker \\
Clotrimazole (Canesten) & Bayer \\
Diododehydroxyquinoline & May and Baker \\
Iodoform & May and Baker \\
Mepacrine mesylate & May and Baker \\
Metronidazole (Flagyl) & May and Baker \\
Neoarsphenamine bromide & May and Baker \\
Nystatin & Squibb \\
Quinine sulphate & May and Baker \\
Rubidomycin (Cerubidin) & May and Baker \\
Sulphacetamide & May and Baker \\
Sulphadiazine & May and Baker \\
Trifluorothymidine & Sigma \\
5-fluorocytosine (Alcobon) & Roche \\
\hline
\end{tabular}

Table III Compounds with no consistent amoebicidal or cysticidal activity at $10^{3} \mu \mathrm{g} / \mathrm{ml}$ or less

\section{Discussion}

The results obtained are in general compatible with those of other authors but tend to be less optimistic due to the use of a limited 48-hour exposure to the compound under test and a more rigorous assessment by $100 \%$ amoebicidal or cysticidal action. Some of the more important differences and agreements with other authors' results are as follows:

Casemore (1970) did not find neomycin active at $100 \mu \mathrm{g} / \mathrm{ml}$ whereas in our tests $1-10 \mu \mathrm{g} / \mathrm{ml}$ inhibited all three Acanthamoeba strains, although $2 \times 10^{2}$ $\mu \mathrm{g} / \mathrm{ml}$ or greater was required for CC activity. Conversely, we could not confirm the activity of 5fluorocytosine that he observed. This may well have been due to cytosine residues in our cultures. We agree with Casemore that the activity of sulphonamides in vitro is weak and inconstant, although Culbertson et al (1965) found that sulphadiazine was protective in vivo for mice inoculated with $A$. castellanii Al.

The use of acriflavine was suggested by Červa's (1969) observation on the in vitro efficacy of Gonacrine, a European trade name of Specia, France, for acriflavine.

Paromomycin is very promising in vitro, as Červa (1969) found, especially in the broth culture tests, but the clinical experience of Jones (1973) has been disappointing.

As regards the nine compounds with appreciable activity that seem worthy of further investigation, we hope that our results will act as a guide for the further work that needs to be done. In vitro activity is, how- 
ever, not necessarily indicative of in vivo action, as, for example, Jamieson (1975) found with clotrimazole and $N$. fowleri, nor are animal experiments necessarily applicable to man.

It is of interest that the patient Elliott did not lose her eye, probably because the progress of the infection was halted by removal of the ulcerated cornea before a replacement graft, almost certainly before trophozoites had penetrated to the anterior chamber, and postoperative treatment included Neosporin drops.

In repeated experiments we have found that Neosporin, and its constituents neomycin and polymyxin, have $100 \%$ amoebicidal activity at concentrations around $10^{3} \mu \mathrm{g} / \mathrm{ml}$. It seems plausible that the combination of surgical removal of the infected area of cornea, coupled with antibiotic therapy, may have enabled this infection to be cured. If so, this may be the first successful treatment.

Five confirmed Acanthamoeba eye infections in this country and the USA within about 18 months suggest that further infections are to be expected.

Early diagnosis is possible and should allow successful treatment, possibly by courses of more than one of these compounds, monitoring for eradication of infection by repeated stained films and cultures.

We are especially indebted to Air Vice Marshal W. P. Stamm and Dr D. C. Warhurst for cultures and helpful advice; also to $\mathrm{Dr}$ J. A. McFadzean and Mr S. Squires, May and Baker Ltd, Dr J. Garrod,
Roche Ltd, and Dr D. S. Good, Bayer UK Ltd for therapeutic compounds and advice on their use.

\section{References}

Apley, J., Clarke, S. K. R., Roome, A. P. C. H., Sandry, S. A., Saygi, G., Silk, B., and Warhurst, D. C. (1970). Primary amoebic meningoencephalitis in Britain. Brit. med. J., 1, 596-599.

Carter, R. F. (1969). Sensitivity to amphotericin B. of a Naegleria sp. isolated from a case of primary amoebic meningoencephalitis. J. clin. Path., 22, 470-474.

Carter, R. F. (1972). Primary amoebic meningoencephalitis. Trans. roy. Soc. trop. Med. Hyg., 66, 193-208.

Casemore, D. P. (1970). Sensitivity of Hartmannella (Acanthamoeba) to 5-fluorocytosine, hydroxystilbamidine, and other substances. J. clin. Path., 23, 649-652.

Cerva, L. (1969). The effect of some drugs on the growth of the pathogenic strain of Hartmannella (Acanthamoeba) castellanii in vitro. Folia parasit. (Praha), 16, 357-360.

Culbertson, C. G., Holmes, D. H., and Overton, W. M. (1965). Hartmannella castellanii (Acanthamoeba sp.): preliminary report on experimental chemotherapy. Amer. J. clin. Path., 43, 361-364.

Jamieson, A. (1975). Effect of clotrimazole on Naegleria fowleri.J. clin. Path., 28, 446-449.

Jones, D. B. (1973). Unpublished communication read at Ocular Microbiology and Immunology Group in Dallas, Texas, U.S.A. October 1973.

Nagington, J., Watson, P. G., Playfair, T. J., McGill, J., Jones, B. R., and Steele, A. D. Mc.G. (1974). Amoebic infection of the eye. Lancet, 2, 1537-1540.

Pereira, M. S., Marsden, H. B., Corbitt, G., and Tobin, J. O'H. (1966). Ryan virus: a possible new human pathogen. Brit. med.J., 1, 130-132.

Warhurst, D. C., and Armstrong, J. A. (1968). Study of a small amoeba from mammalian cell cultures infected with 'Ryan virus'. J. gen. microbiol., 50, 207-215. 